10.1515/ausfm-2015-0008

\title{
Intermedia and Intermittency
}

\author{
Bálint Veres \\ Moholy-Nagy University of Art and Design, Budapest \\ E-mail: veresbal@mome.hu
}

\begin{abstract}
It is commonly known that medial reflections have been initiated by attempts to secure the borders of discrete medial forms and to define the modus operandi of each essentialized medial area. Later on, the focus of study has shifted to plurimedial formations and the interactions between predefined medial genres. In the last few decades, taxonomic approaches to various multi-, inter-, and transmedial phenomena dominated the discussions, which offered invaluable support in mapping the terrain, but at the same time hindered the analysis of the ephemeral, time-dependent aspects of plurimedial operations. While we explore the properties of each medial configuration, we lose sight of the actual historical drivers that produce ever-new configurations. My thesis is that any discourse on intermediality should be paralleled by a discourse on cultural intermittency, and consequently, media studies should involve an approach that focuses on the "ecosystem" of the constantly renewing media configurations from the point of view of their vitalizing potential and capability to trigger heightened experiences. This approach draws much inspiration from $\mathrm{K}$. Ludwig Pfeiffer's media anthropology that gives orientation in my paper.
\end{abstract}

Keywords: media anthropology, hybrid media configurations, opera(tic), heightened experience, media dynamics.

Let's start with an imaginary collection of works, highbrow and vernacular as well, that are associated with issues of intermediality produced either digital or analogue ways. First, take two chapters from Don Boyd's 1987 compilation operamovie, Aria; the one directed by Franc Roddam and the one by Jean-Luc Godard. Then add two impressive Heineken video spots about football and classical music (Auditorium, Heineken Italia - JWT Italy, 2010; Legendary Football, Heineken - Wieden + Kennedy, 2011). Then proceed with the "electronic opera," Desniansky Raion (2007) by the French artist Cyprian Gaillard; and complete our tiny collection with Peter Greenaway's 1989 art movie, The Cook, The Thief, His Wife and Her Lover. I have to give a warning: any detailed analyses on the works 
of this imaginary collection have to be prolonged for another time; here I have the opportunity to give merely some preliminary hints.

This selection of works consists of diverse genres such as opera movie, feature movie, documentary, commercial spot, and video installation. No matter how huge the differences are regarding their dimensions, their acknowledged aims, their economic structure, modes of exhibition, projection, staging, the respective audiences of these genres, or the ways their medial factors interact in a process of forming a whole, which is more often heterogeneous than not, and finally, the various ways they are located within their immediate cultural context; for the moment, I am focusing on their commonalities.

What are these? Well, to start with, each is a hybrid media configuration. Each one includes music, or some artistically organized sound. However, none of them can be easily defined strictly along aesthetic features, rather by their respective institutional systems. And even if their relative cultural prestige gained by and through their respective institutional system underscores their differences, from a historical point of view, they seem to be close relatives regarding their past and present cultural reception, characterized by on one hand fascination and antagonism on the other, theoretical defence and wholesale criticism, in short, they were not received with a warm welcome or an easily stabilized cultural status.

\section{On the "Operatic Principle"}

Starting with the oldest of the genres mentioned above, I recall the debates on opera since its onset, which are well known. Its history from the $17^{\text {th }}$ to the $19^{\text {th }}$ century contains an on-going repetition of the so-called opera reform, and even in the 1960's a powerful guru of contemporary music, Pierre Boulez formulated his alleged suggestion as "the most elegant way of solving the opera problem would be to blow up the opera houses" (Levin 2007, 18).

Well, maybe his suggestion arrived far too belatedly, since from a media anthropological perspective developed in K. Ludwig Pfeiffer's The Protoliterary: Steps toward an anthropology of culture (2002) opera, though not physically but as a distinctive genre has been blown up long ago, maybe before its birth but certainly without being terminated, and the genre has been expanded and spread out to the most various cultural fields, including novels, cinema, and even modern sports events. To indicate a historically conceived guiding force in modern media configurations, Pfeiffer borrows a useful term, "operatic principle” from Herbert Lindenberger's landmark studies on opera (Lindenberger 
1984) to point out relevant drivers of interart, intermedial, and wider cultural shifts. Pfeiffer's approach is that of a Nietzschean sort, that is to say a therapeutic one related to the idea of "great health" on a philosophical level (Nietzsche 1974, 346-347). However, in Pfeiffer's argument, the major role is played not by health but by experience, to be more precise, "heightened experience." And opera (with its roots in Greek tragedy) provides a paradigmatic model for the organized western forms of combining engrossing, fascinating, and participatory experiences and heightened vitality on one hand, and cognitive complexity, a site for contemplation and cultivated reception on the other (Pfeiffer 2002, xvi). ${ }^{1}$

Pfeiffer is not interested in any specific media history - to be more precise: in any specific history of whichever art or medium (2002, xix.) - but rather points out that "the question [...] is one of culturally and therefore also personally significant and attractive media configurations" (2002, xviii) which are ideally understood from a universal comparative perspective.

The way opera manages to coordinate, or rather in a coordinated process leaves uncoordinated the antithetical demands of challenging complexity and simplistic appeal, representation and enactment (in other words: "nonacting through acting”), meaning and spectacle, contemplative detachment and psychophysical involvement; ${ }^{2}$ in short, the way opera bridges culture and nature often proved to be so effective in our history that it can rightly be held as a model in

1 "Human beings [...] come most fully alive when there is a coalescence between a biologically grounded but heightened vitality and a spiritualized 'detachment' or 'disinterestedness. "” - writes Pfeiffer referring to John Dewey's 1934 Art as Experience (Pfeiffer 2002, xviii).

2 "It seems difficult for Western cultures to leave the relations between the surface intensities of spectacles and the 'deeper' or 'higher' levels of either rationality or the affective life in a state of cognitive/affective dissonance, inconsistency, or simply indifference" (Pfeiffer 2002, 130). By comparison "Japanese culture, then, would appear as a side-by-side culture. Spectacular noise and elusive interiority, intellectual seriousness and grossest nonsense, elaborate formality and negligent looseness, stylishness, both traditional in the kimono and contemporary in the latest Western outfit, and stylistic incoherence or lack of style coexist in assigned places, but can also be adopted on what appears as the spur of the moment. Spectacles, to some extent, may be charged with vague symbolism. But one has to reckon also with an ultimate magnificent meaninglessness" (2002, 160). Concerning Japanese theatrical forms Pfeiffer stresses as crucial factor that "acting, role playing, 'imitation' (monomane), much as they are necessary and inevitable at a conventional but transitional stage, must disappear at some point. Technically and structurally, this is achieved by limiting role playing to the middle part, relativizing it by the emphasis on dance and music of the initial and later parts. The 'text' can take form and hold only after a musical conception has effectively materialized. Important as the text may be, it does not allow of a linguistic-poetic analysis in its own right. In such ways, a play without play(ing), that is, acting, may emerge" $(2002,147)$. 
respect of analogous cultural formations down to rock concerts and spectacular sports events, the thelos of which is likewise to neutralize, even temporarily, the governing distinctions in everyday life between reality and fiction, authenticity and deceit, self and society, oneself and role (2002, xix, xxiii, 217).

Pfeiffer widens our understanding of opera by locating its anthropological significance on a more global sphere through a masterful comparison to Japanese theatrical forms like Nō and Kabuki, and also to the martial art of Sumō (2002, 125-172). His account of the Kabuki theatre is instructive in terms of the European opera as well: "Kabuki spectacles thrive on the power and refinement of 'visual and aural delight.' Though never totally devoid of what Western terminology would describe as literary elements, the literary aspect is subordinated to 'theatrical effectiveness.' That means, for instance, that plays are tailored to suit the needs and special abilities of star actors, who must be interested in putting on a powerful show. [...] the audience calls out during climactic pauses $(m a)$ or poses (mie), a practice to some residual extent still known in Western opera. Audience response is stimulated by the extreme stylization of physical movement in a both vague and strong sense, however minimalized or even implicit it may be: visual, aural, codified, encoded, and varied during generations of actors' families. Audience response is triggered by and corresponds to levels of stylized exteriority connoting both crudely stereotyped and elusively spiritual sentiments. This institutionalized and open contact between actors (not plays) and audiences appears to be crucial" (2002, 131-132).

From the perspective of the public, Kabuki and Nō also demonstrates an intermittent emancipation or suspension of socioeconomic and political constraints (Pfeiffer 2002, 144). An ideal result of a play, properly characterized by the notion of "elaborate immediacy" $(2002,156)$, should be "the momentary fusion of quasi-transcendental contemplation and aesthetic effect, of concentration and openness, of increased and abandoned distance." Similarly to the Nietzschean notion of "great health," "the audience should feel hana, blossoming" (2002, 147). However, the minimum condition that triggers such an effect is not strictly decided: in the Japanese theatrical arts the staging of a work does not involve a representation of a full text, instead pieces and fragments can be presented as such, likewise in the Western practice of performing individual arias and other excerpts uprooted from whole operas (Pfeiffer 2002, 148).

Many of these features (priority of show over text based representation, stereotyped exteriority and spiritual sentiments, stardom and the suspension of everyday society, overstylization as elaborate immediacy, multisensory media, 
peak experiences, and immediate audience response) are also discussed in Lindenberger's excellent book, Situating Opera (2010), however he has some additional remarks as well. First, opera is not an authorial genre, but rather a temporal result of an ever-changing interplay of numerous co-creators. Secondly, the experience of an opera is a communal one that has to do with the muchdiscussed notion of "sublime," even with the magical and sacral (2010, 59-61, 138). Lastly, Lindenberger underscores that opera's exceptional intensity comes from its unquestionable musical basis that is directly connected to specific brain activity $(2010,115-138)$. Just like Pfeiffer, he too acknowledges that the operatic quality could be found in many derivative media forms, like movies, sports events, rock operas, and various quasi-operas. ${ }^{3}$

One of his examples for quasi-operas, or as he puts them: "not-quite-operas," is particularly interesting. He depicts a museum situation, not unfamiliar to those who have seen Marina Abramović's The Artist Is Present for instance: "Imagine entering a new, much-touted museum show entitled 'The Faust Project.' Although you are expecting something that evokes and/or represents some traditional images associated with the Faust legend, you are unprepared for an alienating combination of musical noises that you hear emanating from the room even before you enter. As you acclimate yourself to this new environment, you notice that what you took to be a museum guard is actually an actor playing a role in the show. [...] Every quarter hour, a laser printer spews out a scientific paper on how some form of life, from birds and reptiles to human beings, can be cloned, and the actor then tacks these papers to the wall [...]. In another corner one finds a display of early editions of texts on the Faust story, from the Faust Book to Goethe's dramatic poem and thence down to the versions by Paul Valéry and Thomas Mann. In the centre of the room there is a segment of a modern laboratory in which a lifesize effigy of a scientist, dressed in sixteenth-century costume, holds a test tube marked 'Homunculus.' Inside the test tube is a glowing light that, in the course of

3 What is more, Pfeiffer takes the view that "the continuing existence of opera in most Western societies hides the fact that its earlier cultural efficiency is nowadays overshadowed by rock music, or the overall effects of film, and probably sports events" (2002, 186-187). And Lindenberger does not disagree: "One might argue, to be sure, that certain films, for instance, those that cultivate advanced modes of visual and audial simulation, have come to rival opera in intensity. And one can speak as well of the communal experience in sports events, in which intensity is achieved through the suspense about a game's outcome and through the bonds created in the stadium by means of the enmity exercised toward the rival team. But the rock concert may well provide the closest analogy to the communal experience of opera. In both cases the audience senses a strong separation between the world of daily routine and the larger-than-life beings [...] who perform before them” $(2010,60)$. 
a few minutes, turns into a bright jewel and ultimately into the shape of a human infant, after which it returns to the glowing light. Six video monitors, each with a different program, allow six different musical embodiments of the Faust story to blast away at once: Liszt's Faust Symphony; Berlioz's La Damnation de Faust; Gounod's Faust; Boito's Mefistofele; the second movement of Mahler's Eighth Symphony; and Busoni's Doktor Faust. [...] All of those practices that we call the arts are in effect brought together in this room [...]. These various arts in effect invade one another. The sounds of the musical versions of the Faust story, as well as of the interviews with scientists, make it difficult to concentrate on any single one. And these cacophonous sounds cause the viewing of the visual materials within the room to be difficult at best" $(2010,102-103)$.

I do not have the space here to quote the text in its entirety, no matter how impressing the juxtapositions and contrasts of the aesthetic, medial, historical, and technical components are, that Lindenberger enumerates in order to picture the idea of a hybrid exhibition in which the most important fact is the violation of media borders. At the end of his description Lindenberger remarks: "You may wonder where and when this exhibition took place." Then reveals himself: "In fact, I have set up this scenario as a means of showing how opera might participate in a typically contemporary museum project in which all manner of borders are aggressively crossed" $(2010,104)$.

Lindenberger's fanciful idea on The Faust Project can be held as a justified instance of the "operatic" as long as we understand opera as a principle rather than a closed genre. Aiming to grasp the unique power of my examples from Godard and Greenaway to Gaillard and the Heineken spots, Lindenberger's suggestion seems perfectly appropriate. To me "operatic" proves to be a more apt, historically informed term for the phenomena discussed under the labels of "hybrid," "multimodal," "interart," and the like.

\section{Beyond Opera}

However we should not stop here, the long line from Monteverdi's early operas to the space operas of George Lucas and all the analogous "operatic" forms that could even passingly be linked to that line, are not capable to monopolize the site where intense aesthetic experience could occur. Pfeiffer, following the insights of eminent American pragmatists, John Dewey and Richard Shusterman, rightly pointed out that "the media of aesthetic experience extend throughout the realm of everyday life" (2002, xvii.) to appear "in ritual and sports, in parades, fireworks, 
and the media of popular culture, in bodily and domestic ornamentation, from primitive tattoos and cave drawings to contemporary cosmetics and interior decorating, and indeed in the countless colorful scenes and moving events which fill our cities and enrich our ordinary lives" (Shusterman 1992, 47).

And here is a point where we can easily get a link to another important culture analyst, Henry Jenkins, who devoted much of his research to such lowly genres, as wrestling, video games, comic strips, television series, pornography, horror cinema, and the like which are seemingly light years away from opera and its dignified milieu (Jenkins 1992; Jenkins 2002; Jenkins 2006; Jenkins 2007). To my knowledge, Jenkins has never written a page on opera, Japanese theatre or Sumō, but he did write on his beloved popular art forms from vaudeville to wrestling with a cultural anthropological approach very akin to Pfeiffer's. Furthermore, his accounts on the genres in question and his diagnosis on their therapeutic cultural role sound surprisingly similar to Pfeiffer's opinion on opera and Japanese theatre.

Jenkins's notorious term for the heightened aesthetic experience comes from the same register as his examples. "Wow" is the keyword referring to a "sense of wonderment, astonishment, absolute engagement." It "is something to be earned” $(2007,1)$. In The Wow Climax Jenkins recognizes many different cultural forms as wow-worthy, for my purpose here it is enough to refer to his statements on vaudeville and wrestling. His thoughts shed further light on the "operatic" discussed above.

Jenkins's succinct summary on vaudeville, that heavily draws on Gilbert Seldes's classic on the popular arts (Seldes [1924] 1957), would be applicable without substantial change to opera, Kabuki or rock concert and in a lesser degree to music video as well: "Vaudeville was not about telling stories; it was about putting on a show, and more than that, it was about each performer's individual attempt to stop the show and steal the applause. Vaudeville had little use for the trappings of theatrical realism; it was about the spectacular, the fantastic, and the novel. Vaudeville had little use for continuity, consistency, or unity; it was about fragmentation, transformation, and heterogeneity. [...] The vaudeville program was constructed from modular units of diverse material, each no more than twenty minutes long. [...] The entire art of vaudeville performance was structured around achieving that basic emotional impact" (Jenkins 2007, 4-5). Namely, it is the "wow climax." Jenkins's account, which in many respects follows David

4 In Seldes's elaboration: “A moment comes when everything is exactly right, and you have an occurrence - it may be something exquisite or something unnameably gross; there is in it an ecstasy which sets it apart from everything else” $(1957,186)$. 
Bordwell's train of thought on Hong Kong action movie (Bordwell 2000) and Tom Gunning's study on early cinema (Gunning 1986), stresses that the intense emotional impact is the focal point of the activities under investigation. The following characteristics, which are listed in his account (Jenkins 2007, 1-40), are also very familiar in the operatic milieu: momentariness, larger-than-life qualities, ${ }^{5}$ technical virtuosity, wonderment, indeterminacy between narrative and non-narrative, and the demands of visceral rather than intellectual response.

Strange as it may seem, the above mentioned phrases are very accurate in terms of wrestling as well, which is characterized by Jenkins as a horrific hybrid or in-betweenness of sports and entertainment, theater and reality, blow off steam for working class and site of fandom for educated people, morality play and suppressed rebellion, masculine tour de force and latently feminine melodramatic series $(2007,60) .{ }^{6}$ His cultural analysis draws upon Norbert Elias's theory on civilizing process (Elias 2000) and highlights the psychosocial compensatory nature of (even overtly aggressive) sports and spectacles (Elias and Dunning 1986). He is certainly right, however, Pfeiffer can provide further aspects that bring us back to opera and intermediality in general.

According to Pfeiffer, spectacles and "theatrical" quasi-sports events - such as Sumō, the Japanese form of wrestling in relation to which he concludes "the boundaries between fight and spectacular ceremonial are fluid" (2002, 151152) - may gain an overwhelming cultural position due to the fact that certain historically relevant central cultural formations, in the Western world foremost the Greek tragedy and the Christian mass (Lindenberger 2010, 61; Pfeiffer 2002, 173-223), underwent a significant narrowing of their medial effects and capacities, while producing a development towards a bodiless interiority, and consequently drastically lessening the experiential range provided by them. Logical as Pfeiffer's conclusion may be, it is to the same extent non obvious: "the relationship [between mental and somatic cultural aspects] is drawn apart into extremes in literary interiority, on the one hand, and organized sports on

$5 \quad$ An 1630 anonym treatise on opera comments: "it is obvious to every listener that ordinary people do not speak in music but instead plainly [...] speaking in music therefore conforms more with our conceptions of superhuman characters than with our conception and manifest knowledge of everyday men, because harmonic discourse is higher, more masterful, sweeter, and more noble than everyday speech, we attribute it, by means of certain connate sense, to the more sublime and divine characters" (Il corago, translated and quoted in Tomlinson 1999, 24).

6 Roland Barthes also compared WWF wrestling to plays of Moliere and Racine: “There are people who think that wrestling is an ignoble sport. Wrestling is not a sport, it is a spectacle, and it is no more ignoble to attend a wrestled performance of Suffering than a performance of the sorrows of Arnolphe or Andromaque” (Barthes 1982, 23). 
the other" $(2002,120)$. Thus he complements the psychosocial argument with a medial one that sheds light on media dynamics from a historical perspective, which is the topic of my closing chapter.

\section{Medial Therapies}

Pfeiffer argues that the diverging tendencies toward the spectacular on one hand and the spiritual or literary on the other resulted in an urging demand for counteracting media trends that are able to reconcile again spiritual refinement with performativity and strong feelings. This counteraction is always a kind of therapy, psychosocial and medial at once, as it is most obvious in Wagner's concept of the Gesamtkunstwerk (Pfeiffer 2002, 127). Following Pfeiffer, I suggest using the word "operatic" to indicate the historical-medial side of these cultural dynamics. It also has to remind us of the etymological source of the word: that is the plural of the Latin opus; ergo "operatic" is a word indicating such cultural processes and means that can trigger or allow a heightened experience, and are characterized by plurality. Although the media are the foremost means of psychosocial self-therapy, their effects are far from being stable. From an anthropological point of view there is no direct association between any given medium and medial effect, and most importantly stability of effects cannot be ascribed to any medium (Pfeiffer 2002, xiii, 145). And this fact leads us to the aesthetics of reception, since it is evident that media phenomena are to be understood from the perspective of the audience. It also can be stated that the "operatic" media phenomena are the ones that can produce the most intensive, powerful, and balanced combined effects of the conflicting cultural tendencies that are discussed in Hans Ulrich Gumbrecht's influential book, Production of Presence (2004) under the labels of "presence" and "meaning." However, the accumulated aesthetic effects provided by plural cultural formations (i.e. "operas" in the broadest sense) are extremely temporal and turn into entropy in an intermittent way. The term "inter-media" indicates in itself this temporality: "media" refers to something that is in-between, while "inter" also refers to a state of in-betweenness. However in the first case we have something that operates in a socially encoded way, while in the second case this operation lacks conventionality, or at least suspends the social, psychological, and cultural pressures. Thus media as such possess the ability to mediate in an organized cultural context, while "inter" refers to a transitional state where such ability not only exponentially increases but is also counteracted by the suspension of a consensual mediation. 
Thus, media can be not only the subject but also the object of a therapy. "Hair of the dog" - as the saying goes; that is media have to perform their own selftherapy, the paradigmatic model of which became the birth of the European opera in Italy at the turn of the $16^{\text {th }}$ century. It occurred as a medial treatment exercised on verbal theatre that was considered powerless (Pfeiffer 2002, 182183). The aim of the Camerata in Florence was to revitalize the language of poetry by enriching it with its forgotten musical qualities. The point of this medial therapy is very easy to understand if we consider the much circulating late-renaissance gnostic writings like The Corpus Hermeticum that influenced the initial ideas of the resuscitating of Greek tragedy. Here is an excerpt from the 16th chapter: "Turned into our own native tongue, the sermon (logos) keepeth clear the meaning of the words (logoi) [at any rate]. For that its very quality of sound, the [very] power of the Egyptian names, have in themselves the bringing into act of what is said. As far as, then, thou canst, O King - (and thou canst [do] all things) - keep [this] our sermon from translation; in order that such mighty mysteries may not come to the Greeks, and the disdainful speech of Greece, with [all] its looseness, and its surface beauty, so to speak, take all the strength out of the solemn and the strong - the energetic speech of Names. The Greeks, O King, have novel words, energic of 'argumentation' [only]; and thus is the philosophizing of the Greeks - the noise of words. But we do not use words; but we use sounds full-filled with deeds" (The Definitions of Asclepius unto King Ammon. In Corpus Hermeticum, 267). The statements on the Greeks characterized as disdainful and superficial in this text may seem contradictory to the Florentine intentions towards resuscitating Greek tragedy, or more precisely the culture of mousikē (Murray and Wilson 2004), but the misunderstanding can be avoided if we recognize that in the context of the early opera Egyptian magical language stands for the lost power of Greek tragedy.

The initial operatic therapy can be seen as a striving for a powerful and spiritual spectacle that is able to neutralize the opposition of representation and deed, or meaning and presence in the Gumbrechtian terms. Do not forget: opera was accidental, however the kind of media-accident opera exemplifies is far from being accidental, rather a necessity. The thesis of media-intermittency reads as follows: "anthropologically, the most 'occasionalist' [or the most intermittent - in my wording] media and forms of art are the most durable” (Pfeiffer 2002, 189). What is more, we could say that the intermittency that characterizes many Western hybrid media configurations from Spanish fiestas, through British court masques to the American vaudeville or WWF wrestling is one of the main features 
and drivers of the Western media dynamics. Media do perform self-therapies from time to time, but these treatments never prove to be final. Pfeiffer warns about the fragility of opera and its "intermittent collapse" (2002, 222), he also shows Kabuki's transient nature from the public's perspective, ${ }^{7}$ and in general "the potential instability of 'aesthetic' effects [that] are not rooted in some stable or generalized significance” $(2002,161)$.

Here is a question: what might be the causes of the media dynamics that I am referring to here as "intermittency?" I believe, three possible answers offer themselves. The first comes from the argumentation Marshall McLuhan set up stressing the basic human need for awe and wonder: "The crossings or hybridizations of the media release great new force and energy as by fission or fusion. [...] The fact that they do interact and spawn new progeny has been a source of wonder over the ages" (McLuhan 1994, 48-49). Media can produce the expected psychophysical energy only in newer and newer configurations. However, these always tend to reproduce the oppositions of heightened (literary) complexity and spectacular yet often boring performativity, like the division between opera seria and opera buffa, or grand opera and operetta, or modern novel and cinema. ${ }^{8}$

The second answer could also be derived from McLuhan's theses: it stresses the Western pressure for innovation, which is a consequence of a pervasive conception of history as progression. Hybridisation of media thus could be understood as a terrain of innovation that results in aesthetic shock effects that are highly exposed to quick inflation (Bürger 1984, 15-34).

And lastly, the third answer focuses on the historical origin of the shocking aesthetics of medial hybrids, which is Romanticism. It substituted the age-old artistic principle of mimēsis (imitation) with a new principle of expression warranted by the genius himself who is not bound by the rules or limitations of any genre or medium. As Schiller writes in his $22^{\text {nd }}$ Letters upon the Aesthetic Education of Man (1795): "In every art, the perfect style consists in the knowledge how to remove specific barriers, while not canceling at the same time the individual advantages of the art, and how to give it a more general character by a

7 "[Kabuki] is not solidly anchored in some larger, coherent cultural context. If its spectacular potential is more directly powerful, it is equally unstable, liable to be lost or regained in rather haphazard fashions" $(2002,149)$.

8 A phrase from Robert Warshow's The The Immediate Experience (2001 [1962], xli) proves to be illuminating in respect to both the insufficient and compensatory character of our modernity: "I have not brought Henry James to the movies or the movies to Henry James, but I hope I have shown that the man who goes to the movies is the same as the man who reads James." 
wise use of what belongs to it specially." ${ }^{\text {"9 }}$ Romanticism initiated an aesthetics of transgression that played out its cards not only in terms of shocking subjects or revolutionary political intentions but also in terms of dissolving the dichotomies between one art and the other, art and technology, art and life, and the like.

The examples of necessarily intermittent aesthetics of transgression go on and on and have long ceased being confined to the areas of art in its narrow sense. ${ }^{10}$ Pfeiffer recalls for instance the theatrical ideas of Brecht who spoke of theatre "as a sports institution,"11 and here, if I had the adequate space, I would analyse the way Franc Roddam in his chapter of Aria tries to cure and make Wagner's Liebestod digestible for the MTV Generation by impressive cinematography, music video cut, and filmic narration (Citron 2010, 63-76) and also the way Godard, in the same movie, interpolates modern body-building and baroque operatic yearning into each other in an experimental way (Cook 1998, 215-254), or again the way Heineken Italia in its 2010 Cannes Media Gold Lion commercial spot Auditorium stages the rivalry between highbrow arts and football, bringing out a musically and theatrically heightened football broadcast as winner in an extraordinary witty documentary style, and also the way Heineken continues this track in the 2011/12 UEFA Champions League football season campaign that displays legendary football players in opulent opera interiors promoting football as a contemporary incarnation of that reputable art form. I would also analyse the way Cyprian Gaillard and the composer and former opera singer, Koudlam at a memorable part of their dystopic "electronic opera" Desniansky Raion create a strange, delicate, and fragile in-betweenness of different genres such as historical painting, tableau vivant, amateur documentary film and music video showing scenes of street fight between adversary gangs of football hooligans. And lastly I would indulge myself in Peter Greenaway's peerless masterpiece, The Cook, The Thief, His Wife and Her

9 "Darin eben zeigt sich der vollkommene Stil in jeglicher Kunst, dass er die spezifischen Schranken derselben zu entfernen weiß, ohne doch ihre spezifischen Vorzüge mit aufzuheben, und durch eine weise Benutzung ihrer Eigentümlichkeit ihr einen mehr allgemeinen Charakter erteilt.” Friedrich Schiller, Über die ästhetische Erziehung des Menschen, in einer Reihe von Briefen, 1795, S. 44. http://www2.ibw.uni-heidelberg. de/ gerstner/Schiller_Aesthetische_Erziehung.pdf - my translation. Last accessed 23. 09. 2014.

10 That is why Pfeiffer prefers the term media over the arts that always produced in its cultural and conceptual history such dichotomies as high arts and popular arts, arts and crafts, autonomous arts and applied arts, etc. (Pfeiffer 2002, xiv).

11 "His slogan of the 'theater as a sports institution' or as sports itself starts from the diagnosis that people do not have fun in the theater because they go there for the wrong reasons. They are not geared - and neither are most plays and theatrical productions themselves - to the 'fascinating reality' that the sports arena produces or 'stages,' especially, for Brecht, in boxing” (Pfeiffer 2002, 150). 
Lover, in which he treats feature film in an ambitious way: that of the opera using pompous, over-stylized staging, to be more precise: processional staging, excessive, operatic subject, fascinating costumes by Jean-Paul Gaultier, tableaux vivants, ${ }^{12}$ sequences edited similarly to a music video, musical leitmotivs, castrato-like aria (composed by Michael Nyman), and some not less virtuoso "post-operatic" oral utterances (including belch, munching, and all the noises you can imagine around a majestically-laid banquet table) brilliantly performed by Michael Gambon and his co-actors. It is important to notice: the unusual interplay of the above mentioned components do not help but hinder the narrative development, rendering Greenaway's film more image- and music-centered than plot-based (Turi 2010) and his usage of music suggests throughout a highly operatic belief that the noblest ideas and feelings are not communicable via verbal language, only by music. ${ }^{13}$

At the beginning I promised analyses of the works mentioned above, more precisely I have already indicated that these analyses will not be performed. Instead, I tried to delineate an intellectual framework in which these analyses could be implemented. However, it seems to me worthwhile to raise the question, whether it is a more appropriate and rewarding treatment of these artworks if they are scrutinized by close readings and refined interpretations or if it is better for our cultural welfare to leave them to exert their (presence) effects on us without any distancing gesture. I am inclined to leave this question open.

\section{References}

Barthes, Roland. 1982. A Barthes Reader. New York: Hill and Wang.

Bordwell, David. 2000. Planet Hong Kong: Popular Cinema and the Art of Entertainment. Cambridge: Harvard University Press.

12 The whole scenery of the scenes in the restaurant dining room is derived from Frans Hals's picture, The Banquet of the Officers of the St George Militia Company in 1616, a wall-sized reproduction of what is visible at all times in the background.

13 It is not surprising if we consider that The Cook... is his last direction before he started writing his ten opera libretti in the early 90s. Zita Turi notes that "Greenaway's attraction to the Renaissance and Baroque is widely known: the late Renaissance and more notably the Baroque were periods in which the arts were united by intermediality. This included the fusion of visual, audible and written mediums, which competed with, yet also complemented one another and Greenaway considers opera to be the most outstanding example of this artistic synthesis. In his films, such as The Cook, The Thief, His Wife and Her Lover, music is fundamental to the film narrative and the tunes resemble, on the one hand, operas and, on the other hand, they imitate medieval liturgical songs and psalms” (Turi, 2010). 
Bürger, Peter. 1984 [1974]. Theory of the Avant-Garde. Manchester: Manchester University Press.

Citron, Marcia. 2010. When Opera Meets Film. Cambridge: Cambridge University Press.

Cook, Nicholas. 1998. Analyzing Musical Multimedia. Oxford: Clarendon Press.

Elias, Norbert. 2000. The Civilizing Process. Sociogenetic and Psychogenetic Investigations. Oxford: Blackwell.

Elias, Norbert and Eric Dunning. 1986. The Quest for Excitement: Sport and Leisure in the Civilizing Process. New York: Basil Blackwell.

Gumbrecht, Hans Ulrich. 2004. Production of Presence. Stanford: Stanford University Press.

Gunning, Tom. 1986. The Cinema of Attractions: Early Film, Its Spectator, and the Avant-Garde Wide Angle vol. 8 nos. 3\&4 (Fall): 56-62.

Jenkins, Henry. 1992. Textual Poachers: Television Fans $\&$ Participatory Culture. New York: Routledge.

Jenkins, Henry. 2002. Hop on Pop: The Politics and Pleasures of Popular Culture. Duke University Press.

Jenkins, Henry. 2006. Fans, Bloggers, and Gamers: Exploring Participatory Culture. New York: New York University Press.

Jenkins, Henry. 2007. The Wow Climax: Tracing the Emotional Impact of Popular Culture. New York: New York University Press.

Levin, David J. 2007. Unsettling Opera. Chicago: The University of Chicago Press. Lindenberger, Herbert. 1984. Opera: The Extravagant Art. Ithaca: Cornell University Press.

Lindenberger, Herbert. 2010. Situating Opera: Period, Genre, Reception. Cambridge: Cambridge University Press.

McLuhan, Marshall. 1994 [1964]. Understanding Media. Cambridge: The MIT Press.

Mead G. R. S.: Corpus Hermeticum. 1906. http://gnosis.org/library/grs-mead/ TGH-v2/th231.html. Last accessed 23. 09. 2014.

Murray, Penelope and Peter Wilson, eds. 2004. Music and the Muses. Oxford: Oxford University Press.

Nietzsche, Friedrich. 1974. Gay Science. translated by Walter Kaufmann. New York: Vintage.

Pfeiffer, K. Ludwig. 2002. The Protoliterary. Steps toward an Anthropology of Culture. Stanford: Stanford University Press. 
Schiller, Friedrich. 1795. Über die ästhetische Erziehung des Menschen, in einer Reihe von Briefen [title].

http://www2.ibw.uni-heidelberg.de/ gerstner/Schiller_Aesthetische_ Erziehung.pdf. Last accesed 23. 09. 2014.

Seldes, Gilbert. 1957 [1924]. The Seven Lively Arts. New York: Sagmore Press.

Shusterman, Richard. 1992. Pragmatist Aesthetics: Living Beauty, Rethinking Art. Cambridge, Mass.: Blackwell.

Tomlinson, Gary. 1999. Metaphysical Song. An Essay on Opera. Princeton: Princeton University Press.

Turi, Zita. 2010. Metamorphosis and Identity - "Cinetheatrical" Spaces in Peter Greenaway's The Baby of Mâcon. Forum. University of Edinburgh Postgraduate Journal of Culture $\&$ the Arts. Issue 10.

http://www.forumjournal.org/site/issue/10/zita-turi. Last accesed at 23. 09. 2014. Warshow, Robert. 2001 [1962]. The Immediate Experience. Cambridge: Harvard University Press. 